\title{
Evaluation of ventricular systolic dysfunction as a risk factor for acute kidney injury in intensive care unit
}

\author{
Ahmed Aly Obiedallah', Ashraf Anwar E. L. Shazly², Noura Gamal Nasr ${ }^{3,4^{*}}$ and Essam M. Abdel Aziz ${ }^{2}$
}

\begin{abstract}
Background: Heart failure (HF) is a major health problem. Cardiac and renal diseases interact in a complex bidirectional manner in both acute and chronic settings. Renal dysfunction in the setting of heart failure, termed the cardio renal syndrome (CRS), has been considered consequence of left ventricular dysfunction (LVD), whereby decreasing cardiac output (COP) results in renal under perfusion and consequent decreased glomerular filtration rate (GFR).

Main body of the abstract: This study showed that 500 patients were admitted to internal care unit (ICU), and out of them, 100 (20\%) patients developed acute kidney injury (AKI) while 400 (80\%) patients did not develop AKI. It is also showed that 67 (67\%) of those with AKI and 100 (25\%) of those with no-AKI had baseline ventricular systolic dysfunction, left ventricular dysfunction (LVD), right ventricular dysfunction (RVD), and biventricular dysfunction (BiVD)presented in 23 (23\%), 16 (16\%), and 28 (28\%) patients of AKI group, respectively, and presented in 60 (15\%), 30 (7.50\%), and 10 (2.50\%) patients, respectively, in patients without acute kidney injury (AKI)
\end{abstract}

Short conclusion: Our study revealed that AKI has highest incidence in patient with biventricular dysfunction followed by left ventricular dysfunction and lastly those with right ventricular dysfunction.

Keywords: Acute kidney injury, Ventricular systolic dysfunction, Chronic kidney disease

\section{Background}

Renal dysfunction in the setting of heart failure (HF), termed as cardio renal syndrome (CRS), has traditionally been considered a consequence of left ventricular dysfunction (LVD), whereby decreasing cardiac output (COP) results in renal under perfusion and consequent decreased glomerular filtration rate (GFR) [1].

However, emerging data have highlighted the importance of the right ventricle; right ventricular dysfunction can lead to renin-angiotensin aldosterone system (RAAS) activation, sodium retention, and volume overload. With the development of venous congestion in renal dysfunction, peripheral edema and increased central venous pressure (CVP) would

\footnotetext{
*Correspondence: noura.victory@gmail.com

${ }^{3}$ Faculty of Medicine, Assiut University, Assiut, Egypt

${ }^{4}$ Department of Internal Medicine, Faculty of Medicine, Assiut University

Hospitals, Assiut, Egypt

Full list of author information is available at the end of the article
}

be associated with a higher risk of acute kidney injury (AKI) [2].

Cardio renal syndromes (CRS) are broadly divided into two main groups, cardio-renal and reno-cardiac CRS, on the basis of the premium mavens of disease (cardio or renal). Both cardio-renal and reno-cardiac CRSs are then divided into acute and chronic, according to disease's onset. Type 5 of CRS is defined as simultaneous cardiorenal involvement induced by systemic disease [3].

\section{Methods}

\section{Study design}

A randomized prospective cohort study was performed at intensive care units (ICUs) of Internal Medicine Department, from January 2018 till 2019.

\section{Springer Open}

() The Author(s). 2021 Open Access This article is licensed under a Creative Commons Attribution 4.0 International License, which permits use, sharing, adaptation, distribution and reproduction in any medium or format, as long as you give appropriate credit to the original author(s) and the source, provide a link to the Creative Commons licence, and indicate if changes were made. The images or other third party material in this article are included in the article's Creative Commons licence, unless indicated otherwise in a credit line to the material. If material is not included in the article's Creative Commons licence and your intended use is not permitted by statutory regulation or exceeds the permitted use, you will need to obtain permission directly from the copyright holder. To view a copy of this licence, visit http://creativecommons.org/licenses/by/4.0/. 


\section{Subject}

The study included 500 patients that were admitted to ICU for different causes. Patient with end stage renal disease (ESRD), chronic kidney disease (CKD), AKI with post-renal cause, AKI due to other causes rather than ventricular dysfunction, and lastly cirrhotic patient were excluded from this study.

\section{Biochemical assay}

All patients included in the study were subjected to careful history taking, clinical examination, and different laboratory investigations which include

- Random blood glucose, hemoglobin, blood urea, and serum creatinine.

- The baseline value of the estimated glomerular filtration rate (eGFR) was calculated using the Chronic Kidney Disease Epidemiology Collaboration equation (CKD_EPI).

\section{Cardiac investigations}

- Twelve lead ECG, cardiac enzyme evaluation (total creatine phosphokinase CK-MB, lactate dehydrogenase, and troponin I.

- Echocardiography (EF \% ejection fraction, TAPSE (tricuspid plane annular systolic excursion). PWT: posterior wall thickness; LVESD: left ventricular end systolic diameter; LVEDD: left ventricular end diastolic diameter; LAVI: left atrial volume index). According to American society of Echocardiology (ASE) guidelines define an abnormal $\mathrm{EF}$ as $<55 \%$, with the cutoffs for moderately abnormal and severely abnormal at $44 \%$ and $30 \%$, respectively. TAPSE: of $<17 \mathrm{~mm}$ indicates RV dysfunction [4].

- The primary outcome will be AKI during the first 7 days of ICU care, as defined by an increase of $\geq 0.3$ $\mathrm{mg} / \mathrm{dl}$ in serum creatinine within $48 \mathrm{~h}$ of ICU admission, an increase of $\geq 50 \%$ within 7 days of ICU admission, or acute dialysis, in keeping with the kidney disease improving global outcomes guidelines KDIGO [5].

\section{Statistical analysis of data}

Data was collected and analyzed those using SPSS (Statistical Package for the Social Science, version 20, IBM, and Armonk, NY). Continuous data was expressed in form of mean $\pm \mathrm{SD}$ or median (range) while nominal data was expressed in form of frequency (percentage).

Chi-squared test was used to compare the nominal data of different groups in the study while Student's t test was used to compare mean of different two groups.

Multivariate regression analysis was used to determine the independent risk factors for prediction of development of AKI. Level of confidence was kept at $95 \%$ and hence, $P$ value was significant if $<0.05$.

\section{Results}

Our study showed that 500 patients were admitted to ICU, out of them; 100 (20\%) patients developed AKI while $400(80 \%)$ patients did not develop AKI. Our study revealed that mean age of patients with AKI was $65.78 \pm$ 12.98 years and majority $(70 \%)$ of them was males with mean body mass index were $25.67 \pm 2.34 \mathrm{~kg} / \mathrm{m}^{2}$. In case of those with no-AKI, mean age was $55.87 \pm 11.10$ years with mean body mass index was $26.09 \pm 3.30 \mathrm{~kg} / \mathrm{m}^{2}$ and also, majority (60\%) of them was males (Fig. 1, Table 1).

It was noticed that in majority of cases (70\% of those with AKI and $69 \%$ of those with no-AKI) was admitted secondary to acute coronary syndrome. Pulmonary embolism and cerebrovascular stroke were the cause of admission in $25(25 \%)$ and $5(5 \%)$ patients with AKI, respectively, and $84(21 \%)$ and $40(40 \%)$ patients with no-AKI, respectively (Table 2 ).

Also, it was noticed that both groups of patients had insignificant differences as regards baseline urea, creatinine, and estimated glomerular filtrate (eGFR). Serum creatinine and blood urea were significantly higher during 3rd and 5th day in patients with AKI than those without AKI while eGFR was significantly higher among patients with no-AKI during 3rd and 5th day than those with AKI (Table 3)

As regards echocardiographic parameters, our study showed that patients with AKI had significantly lower ejection fraction in comparison to those with no-AKI $(49.11 \pm 2.34$ vs. $54.78 \pm 2.78 ; P<0.001)$. It was noticed that left atrial diameter and volume and left ventricular end diastolic/systolic diameter were significantly higher in patients with AKI (Table 4).

As regards ventricular dysfunction, it was noticed that 67 (67\%) of those with AKI and 100 (25\%) of those with

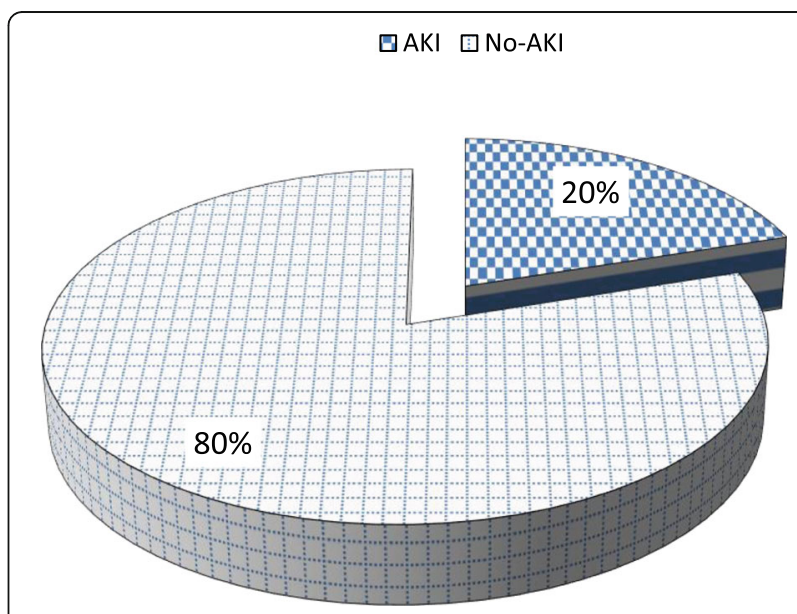

Fig. 1 Frequency of AKI in the current study 
Table 1 Patient characteristics of studied patients

\begin{tabular}{llll}
\hline & AKI $(\boldsymbol{n}=\mathbf{1 0 0})$ & No-AKI $(\boldsymbol{n}=\mathbf{4 0 0})$ & $\boldsymbol{P}$ \\
\hline $\begin{array}{llll}\text { Age (years) } \\
\text { Sex }\end{array}$ & $65.78 \pm 12.98$ & $55.87 \pm 11.10$ & $\mathbf{0 . 0 4} \mathbf{S}$ \\
$\quad$ & & & $0.45 \mathrm{NS}$ \\
$\quad$ Male & $70(70 \%)$ & $240(60 \%)$ & \\
$\quad$ Bemale & $30(30 \%)$ & $160(40 \%)$ & \\
Sody mass index $\left(\mathrm{kg} / \mathrm{m}^{2}\right)$ & $25.67 \pm 2.34$ & $26.09 \pm 3.30$ & $0.33 \mathrm{NS}$ \\
Previous admission & $38(12 \%)$ & $10(10 \%)$ & $0.12 \mathrm{NS}$ \\
Residence & $33(33 \%)$ & $84(21 \%)$ & $\mathbf{0 . 0 4} \mathbf{S}$ \\
$\quad$ & & & $0.09 \mathrm{NS}$ \\
$\quad$ Rural & $66(66 \%)$ & $268(67 \%)$ & \\
$\quad$ Urban & $34(34 \%)$ & $132(33 \%)$ &
\end{tabular}

$S$ significant, value $<0.05$

NS non-significant, value $>0.05$

no-AKI had baseline ventricular dysfunction. Right ventricular dysfunction (RVD), left ventricular dysfunction (LVD), and biventricular dysfunction (BiVD) presented in $16(16 \%), 23(23 \%)$, and $28(28 \%)$ patients of AKI group, respectively, and presented in 30 (7.50\%), 60 (15\%), and 10 (2.50\%) patients, respectively (Table 4).

In our study, it was found that the incidence of the stages of acute kidney injury was 55 (55\%), 25 (25\%), and $20(20 \%)$ stage I, II, and III, respectively. Also, it was found that no significant differences between different stages of AKI as regards echocardiographic parameters with exception of ventricular dysfunction where majority of patients (50\%) with grade III AKI had biventricular dysfunction (Figs. 2 and 3)

\section{Discussion}

Our study included 500 patients, out of which 100 (20\%) patients developed AKI while 400 (80\%) patients did not develop AKI. As shown in Fig. 1, and disagreed with that found by Stanojević et al. (2012) [6], 42.2\% of patients had AKI. Moreover, Waldum et al. (2010) [7] found that AKI (eGFR $<60 \mathrm{ml} / \mathrm{min}$ ) was present in $44.9 \%$ of patients as it was a large cross-sectional study.

We found that patients with AKI had significantly higher mean age in comparison to those without AKI. This is in agreement with the study by Roik et al. (2006) [8]. Various studies have shown a clear age-dependent

Table 2 Causes of admission in studied patients based on development of acute kidney injury

\begin{tabular}{llll}
\hline Causes of admission & AKI $(\boldsymbol{n}=\mathbf{1 0 0})$ & No-AKI $(\boldsymbol{n}=\mathbf{4 0 0})$ & $\boldsymbol{P}$ \\
\hline Acute coronary syndrome & $70(70 \%)$ & $276(69 \%)$ & $\mathbf{0 . 0 9}$ NS \\
Pulmonary embolism & $25(25 \%)$ & $84(21 \%)$ & $\mathbf{0 . 0 9}$ NS \\
CVS & $5(5 \%)$ & $40(10 \%)$ & $\mathbf{0 . 0 9}$ NS
\end{tabular}

Data expressed as frequency (percentage). $P$ value was significant if $<0.05$. non-significant if $>0.05$

$A K I$ acute kidney injury, CVS cerebrovascular stroke
Table 3 Kidney function tests in studied patients based on development of acute kidney injury

\begin{tabular}{|c|c|c|c|}
\hline Variables & AKI $(n=100)$ & No-AKI $(n=400)$ & $P$ \\
\hline \multicolumn{4}{|c|}{ Creatinine (mg/dl) } \\
\hline Baseline & $0.98 \pm 0.11$ & $0.99 \pm 0.10$ & 0.98 NS \\
\hline At 3rd day & $1.22 \pm 0.22$ & $1.01 \pm 0.11$ & $<0.001 \mathbf{S}$ \\
\hline At 5th day & $1.78 \pm 0.44$ & $1.02 \pm 0.12$ & $<0.001 \mathrm{~S}$ \\
\hline \multicolumn{4}{|l|}{ Urea (mg/dl) } \\
\hline Baseline & $12.45 \pm 3.45$ & $11.34 \pm 2.45$ & $0.45 \mathrm{NS}$ \\
\hline At 3rd day & $24.78 \pm 5.55$ & $10.14 \pm 4.44$ & $<0.001 \mathbf{S}$ \\
\hline At 5th day & $33.78 \pm 6.55$ & $11.56 \pm 3.45$ & $<0.001 \mathrm{~S}$ \\
\hline \multicolumn{4}{|c|}{ eGFR $\left(\mathrm{ml} / \mathrm{min} / 1.73 \mathrm{~m}^{2}\right)$} \\
\hline Baseline & $107.98 \pm 10.44$ & $105.5 \pm 5.23$ & $0.09 \mathrm{NS}$ \\
\hline At 3rd day & $88.45 \pm 2.45$ & $102.45 \pm 3.45$ & $<0.001 \mathrm{~S}$ \\
\hline At 5th day & $65.98 \pm 3.45$ & $103.78 \pm 2.22$ & $<0.001 S$ \\
\hline
\end{tabular}

Data was expressed in form of mean (SD). $P$ value was significant if $<0.05$ $A K I$ acute kidney injury, eGFR estimated glomerular filtration rate, $S$ significant, NS non-significant

relationship between AKI and older age. This could be attributed to physiological reduction of eGFR with aging [9].

Our present study revealed that frequency of AKI was insignificantly higher among male patient. It was previously reported that male patients had consistently predominated in reports on the AKI incidence which

Table 4 Echocardiography in studied patients based on development of acute kidney injury

\begin{tabular}{|c|c|c|c|}
\hline Variables & $\mathrm{AKI}(n=100)$ & No-AKI $(n=400)$ & $P$ \\
\hline Ejection fraction (\%) & $49.11 \pm 2.34$ & $54.78 \pm 2.78$ & $<0.001 \mathrm{~S}$ \\
\hline $\begin{array}{l}\text { Left atrial } \\
\text { diameter }(\mathrm{cm})\end{array}$ & $4.98 \pm 0.68$ & $3.01 \pm 0.65$ & $0.03 \mathrm{~S}$ \\
\hline Left atrial volume $\left(\mathrm{cm}^{3}\right)$ & $39.21 \pm 2.62$ & $29.45 \pm 3.33$ & $0.01 \mathrm{~S}$ \\
\hline LAVI $\left(\mathrm{cm}^{3} / \mathrm{mm}^{2}\right)$ & $13.94 \pm 1.34$ & $11.56 \pm 2.30$ & 0.45 NS \\
\hline PWT (mm) & $8.51 \pm 1.07$ & $8.78 \pm 2.11$ & 0.56 NS \\
\hline LVESD (mm) & $39.68 \pm 5.98$ & $31.04 \pm 3.30$ & $<0.001 S$ \\
\hline $\begin{array}{l}\text { LVEDD }(\mathrm{mm}) \\
\text { TAPSE }(\mathrm{mm})\end{array}$ & $\begin{array}{l}53.21 \pm 5.91 \\
16.78 \pm 3.33\end{array}$ & $\begin{array}{l}43.76 \pm 3.33 \\
13.45 \pm 2.34\end{array}$ & $\begin{array}{l}<0.001 S \\
<0.001 S\end{array}$ \\
\hline Ventricular function & & & $<0.001 S$ \\
\hline $\begin{array}{l}\text { Normal biventricular } \\
\text { function }\end{array}$ & $33(33 \%)$ & $300(75 \%)$ & \\
\hline $\begin{array}{l}\text { Right ventricular } \\
\text { dysfunction }\end{array}$ & $16(16 \%)$ & $30(7.50 \%)$ & \\
\hline $\begin{array}{l}\text { Left ventricular } \\
\text { dysfunction }\end{array}$ & $23(23 \%)$ & $60(15 \%)$ & \\
\hline $\begin{array}{l}\text { Biventricular } \\
\text { dysfunction }\end{array}$ & $28(28 \%)$ & $10(2.50 \%)$ & \\
\hline
\end{tabular}

Data was expressed in form of mean (SD). $P$ value was significant if $<0.05 \mathrm{AKI}$ acute kidney injury, PWT posterior wall thickness, LVESD left ventricular end systolic diameter, LVEDD left ventricular end diastolic diameter, LAVI left atrial volume index, TAPSE tricuspid plane annular systolic excursion, $S$ significant, NS non-significant 


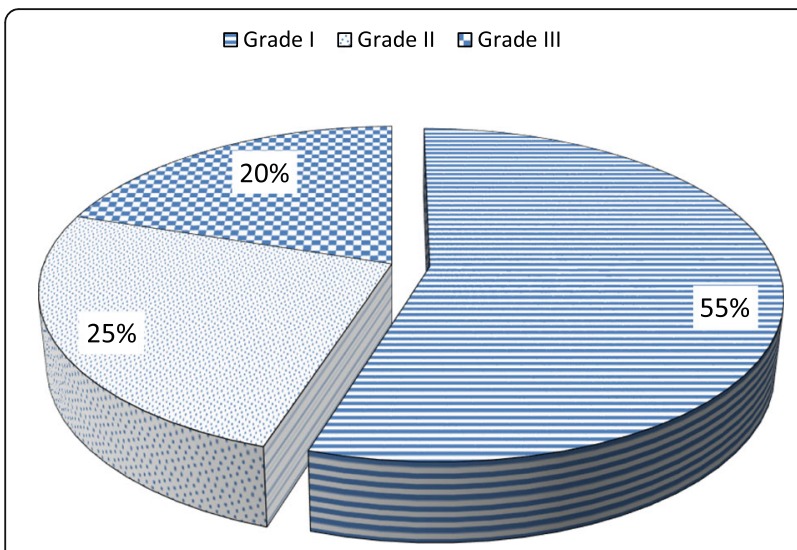

Fig. 2 Stages of AKI in the current study

may be explained by a higher prevalence of smoking and some other risk factors among males [10].

Also, Collins et al. (2011) [11] showed that men were more likely to develop incident of AKI than women. Mallhi et al. (2015) [12] stated that frequency of AKI among males is secondary to males are usually have better access to health care explaining the higher reported incidence of AKI among males.

In our study, patients with AKI had significantly lower ejection fraction in comparison to those with no-AKI. It was noticed that left atrial diameter and volume, TAPSE, and left ventricular end diastolic/systolic diameter were significantly higher in patients with AKI. Tandon et al. (2013) [13] concluded that lower RV longitudinal function (evaluated with TAPSE) was significantly associated with AKI development during a 3-day follow-up.

As previously described, patients with right ventricular dysfunction have a higher risk of AKI due to raised central venous pressure and low cardiac output [14]. As regards frequency of ventricular dysfunction based on AKI in our study, it was noticed that frequency of ventricular dysfunction was more common among those with AKI.

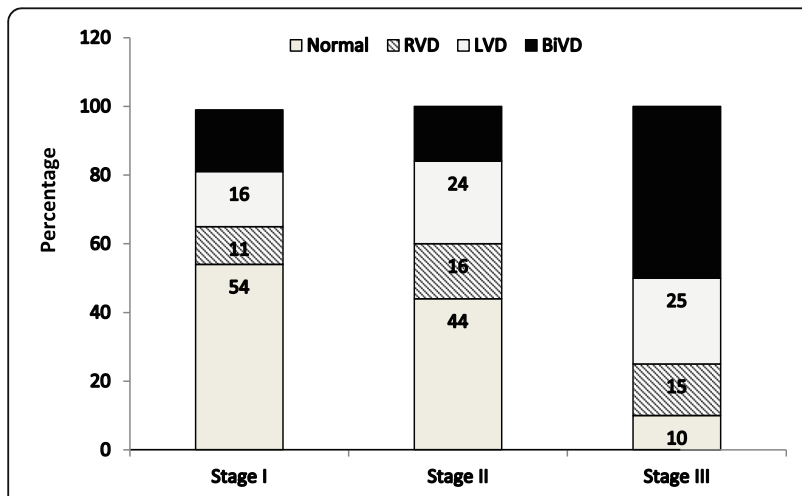

Fig. 3 Frequency of ventricular dysfunction based on stages of AKI
This agreed with a study done by Chen et al. (2017) [15] which included 1879 critically ill patients who underwent echocardiography within $24 \mathrm{~h}$ of ICU admission, $21 \%(n=388), 9 \%(n=167)$, and $13 \%(n=252)$ had isolated right ventricular dysfunction (ILVD), isolated left ventricular dysfunction (IRVD), and BiVD, respectively.

Also, Chen et al. (2017) [15] showed that pulmonary embolism was more common in patients with IRVD (16\%) than in those with other forms of ventricular dysfunction, whereas a diagnosis of myocardial infarction was seen in almost $36 \%$ of patients with ILVD. Blood pressure was lowest and admission serum creatinine level was highest in those with BiVD.

This in contrast with our study, as it was performed in tertiary center with large number of patients admitted with acute coronary syndrome, so we found that majority of cases $(70 \%$ of those with AKI and 69\% of those with no-AKI) was admitted secondary to acute coronary syndrome.

In our study, we showed that majority of patients (50\%) with grade III AKI had biventricular dysfunction. In contrast with our study, Chen et al. 2017 [15] showed AKI tended to be more severe with both IRVD and BiVD. Stage III AKI occurred in 9\% $(n=15)$ and $10 \%(n=26)$ of patients with IRVD and BiVD, compared with $5 \%(n=20)$ and $7 \%(n=78)$ of patients with ILVD and normal biventricular function, respectively. This may be secondary to different sample size, selection bias, and/or lost to follow-up

The main limitations of this study include (1) not performing survival analysis of the enrolled patients, (2) short-term follow-up of patients even those who developed AKI, (3) AKI diagnosis was made by serum creatinine changes, although there might be patients who suffered some degree of kidney damage without having elevated creatinine values, and (4) it was done in only one center.

\section{Conclusion}

AKI is common in patients with ventricular dysfunction. Echocardiography is a simple non-invasive tool that could be used for early detection of AKI among susceptible patients in ICU.

\footnotetext{
Abbreviations

HF: Heart failure; CRS: Cardiorenal syndrome; LVD: Left ventricular dysfunction; COP: Cardiac output; GFR: Glomerular filtration; VSD: Ventricular systolic dysfunction; ICU: Intensive care unit; AKI: Acute kidney injury; CVP: Central venous pressure; AKI: Acute kidney injury; CKD: Chronic kidney disease; ESRD: End stage renal disease; SD: Standard deviation
} 


\section{Authors' contributions}

LA made substantial contributions to the design of the work, the acquisition, analysis, interpretation of data, and was a major contributor in revising the manuscript. AlK made substantial contributions to the design of the work and supervising the work. FRE is the corresponding author, has a major role in collecting the data and laboratory investigations of the patients in the study, had a major role in writing the manuscript, and had a major role in doing the statistical analysis of the data. All authors have read and approved the manuscript.

\section{Funding}

Nil.

\section{Availability of data and materials}

The datasets used and/or analyzed during the current study are available from the corresponding author on reasonable request.

\section{Declarations}

\section{Ethics approval and consent to participate}

The study protocol was approved by the Ethics Review Board of Faculty of Medicine, Assiut University, and informed written consent was obtained from all participants according to the Declaration of Helsinki. The committee's reference number is not available.

\section{Consent for publication}

Not applicable

\section{Competing interests}

The authors declare that they have no competing interests.

\section{Author details}

'Internal Medicine and Cardiology, Faculty of Medicine, Assiut University, Assiut, Egypt. ${ }^{2}$ Internal Medicine and Nephrology, Faculty of Medicine, Assiut University, Assiut, Egypt. ${ }^{3}$ Faculty of Medicine, Assiut University, Assiut, Egypt. ${ }^{4}$ Department of Internal Medicine, Faculty of Medicine, Assiut University Hospitals, Assiut, Egypt.

Received: 27 January 2021 Accepted: 11 June 2021

Published online: 09 August 2021

\section{References}

1. Legrand M, Mebazaa A, Ronco C, Januzzi JL (2014) When cardiac failure, kidney dysfunction, and kidney injury intersect in acute conditions: the case of cardiorenal syndrome. Crit Care Med 42(9):2109-2117. https://doi.org/10.1 097/CCM.0000000000000404

2. Chen KP, Cavender S, Lee J et al (2016) Peripheral edema, Central venous pressure, and risk of AKI in critical illness. Clin J Am Soc Nephrol 11(4):602-608

3. Ronco C, Haapio M, House AA, Anavekar N, Bellomo R (2008) Cardiorenal syndrome. J Am Coll Cardiol 52(19):1527-1539. https://doi.org/10.1016/j.ja cc.2008.07.051

4. Lang RM, Badano LP, Mor-Avi V, Afilalo J, Armstrong A, Ernande L, Flachskampf FA, Foster E, Goldstein SA, Kuznetsova T, Lancellotti P, Muraru D, Picard MH, Rietzschel ER, Rudski L, Spencer KT, Tsang W, Voigt JU (2015) Recommendations for cardiac chamber quantification by echocardiography in adults: an update from the American society of echocardiography and the European association of cardiovascular imaging. Eur Heart J Cardiovasc Imaging 16(3):233-271. https://doi.org/10.1093/ehjci/jev014

5. Kdigo AK (2012) Work Group. KDIGO clinical practice guideline for acute kidney injury. Kidney Int Suppl 2(1):1-38

6. Stanojević D, Apostolović S, Janković-Tomašević R, Šalinger-Martinović S, Pavlović M, Živković M et al (2012) Prevalence of renal dysfunction and its influence on functional capacity in elderly patients with stable chronic heart failure. Vojnosanit Pregl 69(10):840-845. https://doi.org/1 0.2298 NSP1210840S

7. Waldum B, Westheim AS, Sandvik L, Flønæs B, Grundtvig M, Gullestad L, Hole T, Os I (2010) Renal function in outpatients with chronic heart failure. J Card Fail 16(5):374-380. https://doi.org/10.1016/j.cardfail.2010.01.001

8. Roik M, Starczewska MH, Stawicki S, Solarska-Półchłopek A, Warszawik O, Oręziak A et al (2006) Original article The prognostic value of renal dysfunction in patients with chronic heart failure: 12-month follow-up. Kardiologia Polska (Polish Heart Journal) 64(7):704-711

9. Bagshaw SM, George C, Bellomo R, ANZICS Database Management Committee (2007) Changes in the incidence and outcome for early acute kidney injury in a cohort of Australian intensive care units. Crit Care 11(3):R68

10. Ali T, Khan I, Simpson W, Prescott G, Townend J, Smith W, MacLeod A (2007) Incidence and outcomes in acute kidney injury: a comprehensive population-based study. J Am Soc Nephrol 18(4):1292-1298. https://doi. org/10.1681/ASN.2006070756

11. Collins AJ, Foley RN, Herzog C, Chavers B, Gilbertson D, Ishani A, Kasiske B, Liu J, Mau LW, McBean M, Murray A, St. Peter W, Guo H, Gustafson S, Li Q, Li SL, Li S, Peng Y, Qiu Y, Roberts T, Skeans M, Snyder J, Solid C, Wang C, Weinhandl E, Zaun D, Arko C, Chen SC, Dalleska F, Daniels F, Dunning S, Ebben J, Frazier E, Hanzlik C, Johnson R, Sheets D, Wang X, Forrest B, Constantini E, Everson S, Eggers P, Agodoa L (2011) US renal data system 2010 annual data report. Am J Kidney Dis 57(1):A8. https://doi.org/10.1053/ j.ajkd.2010.10.007

12. Mallhi $T H$, Khan $A H$, Adnan AS, Sarriff A, Khan $Y H$, Jummaat $F$ (2015) Incidence, characteristics and risk factors of acute kidney injury among dengue patients: a retrospective analysis. PLoS One 10(9):e0138465. https:// doi.org/10.1371/journal.pone.0138465

13. Tandon R, Mohan B, Chhabra ST, Aslam N, Wander GS (2013) Clinical and echocardiographic predictors of cardiorenal syndrome type I in patients with acute ischemic right ventricular dysfunction. Cardiorenal Med 3(4):239245. https://doi.org/10.1159/000355524

14. Mielniczuk LM, Chandy G, Stewart D, Contreras-Dominguez V, Haddad H, Pugliese C, Davies RA (2012) Worsening renal function and prognosis in pulmonary hypertension patients hospitalized for right heart failure. Cong Heart Failure 18(3):151-157. https://doi.org/10.1111/j.1751-7133.2011.00275.x

15. Chen C, Lee J, Johnson AE, Mark RG, Celi LA, Danziger J (2017) Right ventricular function, peripheral edema, and acute kidney injury in critical illness. Kidney Int Rep 2(6):1059-1065. https://doi.org/10.1016/j. ekir.2017.05.017

\section{Publisher's Note}

Springer Nature remains neutral with regard to jurisdictional claims in published maps and institutional affiliations.

\section{Submit your manuscript to a SpringerOpen ${ }^{\circ}$ journal and benefit from:}

- Convenient online submission

Rigorous peer review

- Open access: articles freely available online

High visibility within the field

- Retaining the copyright to your article

Submit your next manuscript at $\boldsymbol{\nabla}$ springeropen.com 